\title{
MEGAEVENTOS ESPORTIVOS E MODERNIZACÃO TECNOLÓGICA: PLANOS E DISCURSOS SOBRE O LEGADO EM SEGURANCA PÚBLICA
}

\author{
Bruno de Vasconcelos Cardoso \\ Universidade Federal do Rio de Janeiro - Brasil
}

Resumo: $O$ artigo trata dos preparativos de segurança para os megaeventos esportivos a serem realizados no Brasil nos próximos anos, dando ênfase especial à cidade do Rio de Janeiro, e aos processos relacionados à modernização tecnológica. Sendo assim, o planejamento estratégico oficial brasileiro para a Copa do Mundo de 2014 é tomado como objeto privilegiado de análise, assim como a construção de um prédio na região central da cidade, o Centro Integrado de Comando e Controle, apresentado como principal pilar do programa securitário dos megaeventos. A partir disso serão traçadas considerações sobre a desejada e propalada integração institucional, que seria proporcionada pela construção em questão, e constituiria o principal legado em segurança pública a ser deixado pelos megaeventos.

Palavras-chave: legado, segurança pública, tecnologia, vigilância.

\begin{abstract}
The article focuses on security preparations for the sporting mega events to be held in Brazil in the coming years, giving special emphasis to the city of Rio de Janeiro, and to some procedures related to technological modernization. Thus, the official Brazilian strategic planning for the 2014 World Cup is taken as the privileged object of analysis, as well as the construction of a building at downtown, the Integrated Command and Control Centre, presented as the main pillar of mega event's security policies. From this analysis, will be drawn some considerations upon the desired and vaunted institutional integration, which would be provided by the building in question, and would be the main legacy in public safety to be left by mega events.
\end{abstract}

Keywords: legacy, public security, surveillance, technology. 


\section{Consideracõos iniciais}

O presente artigo tem por objetivo discutir alguns importantes aspectos relacionados às preocupações, soluções aventadas e atuação das forças de segurança brasileiras (mais especificamente do Rio de Janeiro), para a realização dos megaeventos esportivos que ocorrerão entre 2013 e 2016 (Copa das Confederações da FIFA, em 2013; Copa do Mundo de Futebol, em 2014, e Jogos Olímpicos, em 2016). Para tanto, serão apresentadas de modo breve algumas discussões que tratam dos planos e atividades de segurança em megaeventos, seguidas de uma análise do Planejamento estratégico de segurança para a Copa do Mundo FIFA Brasil 2014¹ (Brasil, 2012b). Em especial, serão pensados os aspectos relativos aos planos e investimentos em "modernização tecnológica" que têm por objetivo declarado a integração entre as diversas instituições responsáveis pela segurança pública local, apresentada como principal "legado" dos megaeventos para a segurança. Como exemplo específico, o Centro Integrado de Comando e Controle (CICC) do Rio de Janeiro, apontado como pilar do planejamento de segurança, será tratado de forma um pouco mais acurada, no intuito de mostrar algumas importantes questões trazidas ou catalisadas pelos megaeventos vindouros e pela crescente "modernização tecnológica" da segurança pública. A escolha se deve tanto por serem os CICCs, construídos nas 12 cidades-sedes da Copa de 2014, o maior investimento em segurança para os jogos quanto pela continuidade que proporcionam à pesquisa que venho realizando desde 2006, com campo realizado em dois diferentes pontos do sistema de videovigilância policial do Rio de Janeiro. Um deles foi o Centro de Comando e Controle (CCC), que serviu como "piloto" e que vem sendo substituído e significativamente ampliado com a construção do CICC. Dessa forma, a referência a esse contexto etnográfico é constante, tanto na compreensão do tema como na elaboração dos argumentos, ou no recurso a exemplos.

\footnotetext{
Doravante PESCM14.

"Legado" também é uma palavra tratada como uma categoria nativa. Seu sentido será tema de discussão adiante.
}

Horizontes Antropológicos, Porto Alegre, ano 19, n. 40, p. 119-148, jul./dez. 2013 


\section{Megaeventos e seguranca: novos palcos, novos temores, novos gastos}

Giulianotti e Klauser (2009) ressaltam que, desde a escolha da África do Sul como palco das duas principais competições futebolísticas mundiais, a Copa das Confederações (em 2009) e a Copa do Mundo (em 2010), e da Índia (Nova Deli) como sede dos Jogos do Commomwealth (também em 2010), vem ganhando força a ideia de que os megaeventos esportivos representariam uma excelente oportunidade para os países do chamado Global South alavancarem o desenvolvimento local e serem inserido no rol dos "países modernos".

Para a discussão proposta é importante ter em vista que o conceito de moderno (e também o de não moderno) aqui utilizado faz referência não apenas à ideia de "modernização tecnológica", tal como apresentada antes, mas também surge como sinônimo de desenvolvido, pensado por oposição a subdesenvolvido ou a em desenvolvimento, termos mais comumente aplicado a países do que a objetos. As competições a serem realizadas no Brasil nos próximos anos se enquadrariam também nessa nova perspectiva de inserção. No entanto, a categoria utilizada pelos autores, Global South (que, em oposição ao Global North vem substituir a dicotomia que por muitas décadas foi utilizada, entre países desenvolvidos e subdesenvolvidos ou em desenvolvimento), não parece ser adequada. Primeiramente por excluir a Grécia, país que sediou as Olimpíadas de 2004, que se enquadraria no grupo de países não modernos e na argumentação proposta. ${ }^{4}$ Em segundo lugar por não ressaltar de modo suficiente a recente presença dos chamados Brics na organização de megaeventos esportivos, lembrando que além daqueles sediados nos países já citados (Brasil, Índia e África do Sul), em 2008 os Jogos Olímpicos foram realizados na China (Pequim) e em 2018 a Copa do Mundo ocorrerá na Rússia, fazendo com que, em um espaço de dez anos, todos os países identificados como pertencentes a esse "bloco" tenham sediado ao menos uma dessas competições.

\footnotetext{
3 A Copa das Confederações, que reúne os vencedores dos campeonatos continentais, o último campeão mundial, além da seleção do país-sede, ocorre um ano antes da Copa do Mundo e serve como "evento-teste" para a mesma.

4 Vale atentar para o fato de que este país foi um dos pilares da crise econômica atual na comunidade europeia, fator que, segundo Samatas (2011), se deve também aos exorbitantes custos das Olimpíadas de Atenas, em 2004, cujo legado à cidade seria pouco sentido por seus habitantes.
}

Horizontes Antropológicos, Porto Alegre, ano 19, n. 40, p. 119-148, jul./dez. 2013 
Dentro desse panorama, a Copa do Mundo de 2010 teve impacto ainda mais significativo por representar o primeiro megaevento de alcance mundial ocorrido no continente africano, ${ }^{5}$ e também pelo fato de o país-sede ter sido afastado de competições esportivas internacionais por quase três décadas (embora tenha havido uma variação de esporte para esporte; no futebol, ${ }^{6}$ por exemplo, o boicote funcionou de 1963 a 1991) em função de suas políticas de segregação racial. Representou, ao mesmo tempo, uma nova inserção do continente africano no mundo, e um definitivo sepultamento, aos olhos da comunidade internacional, do apartheid.

Outra mudança que vem sendo assinalada é o aumento exponencial dos gastos em segurança (Bennett; Haggerty, 2011; Coaffee; Fussey; Moore, 2011; Cornelissen, 2011; Samatas, 2011). Os atentados terroristas de 11 de setembro de 2001 são apontados, de forma unânime, como o principal fator para essa mudança. O quadro com os gastos absolutos em segurança nos Jogos Olímpicos de 1992 a 2008 demonstra claramente essa transformação: ${ }^{7}$

\begin{tabular}{|c|c|c|c|}
\hline Ano & Cidade & $\begin{array}{c}\text { Orçamento em } \\
\text { segurança (US\$) }\end{array}$ & $\begin{array}{c}\text { Variação em relação } \\
\text { ao evento anterior }\end{array}$ \\
\hline 1992 & Barcelona, Espanha & 66,2 milhões & - \\
\hline 1996 & Atlanta, EUA & 108,2 milhões & $+63,4 \%$ \\
\hline 2000 & Sydney, Austrália & 179,2 milhões & $+65,6 \%$ \\
\hline 2004 & Atenas, Grécia & 1,5 bilhões & $+737 \%$ \\
\hline 2008 & Pequim, China & 6,5 bilhões & $+333,3 \%$ \\
\hline
\end{tabular}

Quadro 1. Variacão dos gastos em segurança nas Olimpíadas de verão (1992-2008) - números absolutos. Fonte: Giulianotti e Klauser (2009, p. 2).

5 Embora a África do Sul tenha sediado a Copa do Mundo de Rúgbi, em 1995, deve-se ressaltar que esse esporte tem a prática muito mais restrita, com adeptos em poucos países (além das ilhas britânicas e de antigas colônias britânicas, as mais tradicionais seleções são da França e da Argentina).

6 Que vem a ser o esporte mais significativo na questão discutida, por ser o mais popular do mundo e por ter sido a Copa do Mundo desse esporte que o país sediou em 2010.

7 Mesmo se os números do Quadro 1 possam ser impressionantes, sua utilização é limitada, posto que não estão deflacionados nem indicam a proporção de gastos em segurança no total dos gastos olímpicos. Mesmo diante de tais limitações, pode-se ter uma ideia do significativo aumento posterior aos ataques de 11 de setembro de 2001 pela variação dos gastos entre Sydney (2000) e Atenas (2004).

Horizontes Antropológicos, Porto Alegre, ano 19, n. 40, p. 119-148, jul./dez. 2013 
Surge então uma situação aparentemente paradoxal: a partir do momento em que os megaeventos tornam-se muito mais custosos, eles passam a ser promovidos por países com recursos financeiros mais escassos. Entretanto, o paradoxo é desfeito pelo discurso que associa os imensos gastos dos anfitriões com a contrapartida do "legado" de infraestrutura a ser deixado. Com a questão da segurança acontece o mesmo. O sistema de videovigilância do Rio de Janeiro, por exemplo, é apresentado como um legado dos Jogos PanAmericanos de $2007^{8}$ - e, mesmo se sua construção foi iniciada de forma independente, dificilmente teria se expandido com a mesma velocidade entre os anos de 2006 e 2007 sem os vultosos recursos recebidos da Secretaria Nacional de Segurança Pública (Senasp), ${ }^{9}$ cujo intuito declarado era promover maior segurança para a cidade durante a competição internacional que ocorreria. No caso dos megaeventos vindouros, os investimentos e estratégias vêm sendo planejados com antecedência e nível de detalhes bastante superior ao que foi visto no Pan de 2007, principalmente por terem alcance, importância e visibilidade muito mais significativas.

Ganham, então, grande relevo os fluxos internacionais de transferência de recursos ligados à questão da segurança, em especial aqueles que concernem ao conhecimento, à tecnologia e ao capital. A transferência tecnológica promove uma imensa movimentação monetária, tendo florescido em razão disso um poderoso mercado de segurança altamente especializado. Como indicam Giulianotti e Klauser (2011, p. 3164, tradução minha),

Esta tendência é canalizada por diretrizes e manuais de políticas específicas [...], que ditam normas padronizadas e procedimentos do processo de licitação para a realização do evento, monitoramento do processo pelos organizadores, mas também uma gama de mecanismos mais informais que facilitam a "aprendizagem institucional" e "rápida transferência de política" (Peck; Theodore, 2001) de evento para evento (feiras de tecnologia, ${ }^{10}$ conferências de especialistas, ${ }^{11}$ exercícios, ${ }^{12}$ etc.). Além desses mecanismos, papel importante é desempenhado

\footnotetext{
Sobre o assunto ver, por exemplo, Coli (2011) e Mendes Afonso e Santos da Silva (2013).

Órgão vinculado ao Ministério da Justiça.

${ }^{10}$ Como, por exemplo, a LAAD Defence \& Security - Feira Internacional de Defesa e Segurança (ver http://laadexpo.com.br).

${ }^{11}$ Como a I Conferência Internacional para a Segurança de Grandes Eventos, realizada em Brasília, em novembro de 2012 (Brasil, 2012).

${ }^{12}$ Como aqueles realizados pelas Forças Armadas brasileiras no Rio de Janeiro, em maio de 2013 (Forças Armadas..., 2013).
} 
pela circulação global de agentes públicos e privados em matéria de segurança, viajando de lugar a outro e de um evento para outro. ${ }^{13}$

Nos casos específicos de Atenas e Pequim, estudados por Samatas (2011), ficam evidenciados alguns aspectos bastante nocivos desses gastos elevados em segurança, tais como o impacto orçamentário - desnecessário e indesejado em matéria de "legado" -, no caso grego, ou a criação de um supersistema estatal de vigilância e controle de dados digitais, pelo governo chinês, ${ }^{14}$ além de um aparelhamento de um regime comunista e não democrático com tecnologia de segurança e espionagem norte-americanos - o que contradiria o discurso "de apoio à democracia" defendido pelos Estados Unidos. O interesse de empresas privadas de tecnologia ${ }^{15}$ cria um cenário de pressão que se mostra incompatível com quaisquer princípios seja de austeridade fiscal, ou de favorecimento à liberdade e democracia.

Para compreender melhor essa relação é preciso ter em mente que três tipos de riscos são comumente identificados, a cada um deles correspondendo diferentes tipos de "legado": a violência política ou o terrorismo; a violência entre/de espectadores; ${ }^{16}$ e a violência urbana e a criminalidade local (Giulianotti; Klauser, 2009). Pensando em termos de legado que o combate a essas ameaças durante os jogos poderá deixar à cidade do Rio de Janeiro,

${ }^{13}$ Podemos lembrar aqui do recente episódio envolvendo as equipes organizadoras dos Jogos Olímpicos em Londres e no Rio de Janeiro, no qual alguns agentes brasileiros foram acusados, e demitidos por causa disso, de copiar ilegalmente informações confidenciais. Sem dúvida, parte dessas proibições diz respeito não à confidencialidade das informações, mas ao interesse posterior em comercializá-las, num processo de agregação de valor ao know-how daqueles que organizaram megaeventos (ver Membros..., 2012).

${ }^{14}$ Conhecidos como "Golden Shield" (videovigilância, escuta telefônica e monitoramento de dados digitais) e "The Great Firewall" (controle estrito sobre a internet).

${ }^{15}$ Como SAIC e Siemens em Athenas 2004 e IBM, General Electric, Nortel, Cisco e outras em Pequim 2008 (Samatas, 2011, p. 3350).

${ }^{16}$ A preocupação com a violência de ou entre torcedores é mais relativa à Copa do Mundo, já que o futebol costuma congregar grupos reconhecidamente violentos de torcedores (o exemplo mais recorrente é o dos hooligans ingleses). É interessante notar que o combate ao hooliganismo foi um excelente campo de testes para o desenvolvimento do vasto sistema de videovigilância em operação na Grã-Bretanha desde meados da década de 1990 (ver Armstrong; Giulianotti, 1998). No Brasil, tal relação também foi apontada por Curi (2012), em sua tese sobre o Estádio Olímpico João Havelange, construído para o Pan de 2007. Para uma visão geral do hooliganismo no mundo, ver Agostino (2002).

Horizontes Antropológicos, Porto Alegre, ano 19, n. 40, p. 119-148, jul./dez. 2013 
o primeiro tipo parece, ao menos momentaneamente, como o mais exógeno ao contexto brasileiro. ${ }^{17}$

Já o segundo tipo de risco, por mais que a violência entre torcedores seja comum nos estádios brasileiros e seus entornos urbanos, não justificaria o investimento financeiro, humano e tecnológico que vem sendo realizado, em especial pelo fato de parte considerável desse trabalho ser incumbência de instituições privadas organizadoras dos eventos - FIFA, Comitê Organizador Local (COL) e, no caso das Olimpíadas, o Comitê Olímpico Internacional (COI) -, já que pelas regras estipuladas por estas, ${ }^{18}$

os órgãos de segurança pública fazem a segurança da cidade e das vias públicas, até a porta dos estádios, e as equipes de segurança privada desempenham suas funções de segurança patrimonial e de vigilância no domínio territorial do estádio. Esse modelo inaugurará um novo conceito de atuação conjunta das forças públicas e privadas. [...] As forças de segurança pública permanecem de sobreaviso e só intervêm quando há grave tumulto e se faça necessária a manutenção da ordem pública, ou quando necessário o emprego do poder de polícia, ou seja, só atuam dentro das instalações esportivas sob demanda. (Brasil, 2012b, p. 44).

Cornelissen (2011, p. 3223), ao explicar e descrever como ocorreu essa parceria público-privado na segurança de algumas áreas na Copa do Mundo de 2010, na África do Sul, fala de uma "suspensão temporária da soberania" sobre determinados espaços da cidade, em favor de "entidades" esportivas transnacionais orientadas por princípios comerciais, ${ }^{19}$ algo que - ao menos em tese - viria a ferir o princípio das forças públicas da ordem.

Algumas semanas antes do início do torneio e durante o evento, certos poderes de segurança foram cedidos para a FIFA e o COL, que obtiveram a jurisdição

${ }^{17}$ O combate ao terrorismo aparece no PESCM14 como atribuição, principalmente, da Polícia Federal, auxiliada pela Agência Brasileira de Inteligência (Abin), e pelas Forças Armadas, especificamente no que tange à proteção das fronteiras e dos espaços aéreo e marítimo.

${ }_{18}$ Ver, por exemplo, as detalhadas Safety regulations, da FIFA (2008), cujo tom explicita o intenso caráter de "deveres e responsabilidades" implicado em sediar um desses megaeventos.

${ }^{19}$ É significativa a referência do PESCM14 ao crime de "marketing de emboscada" (Brasil, 2012b, p. 31), ou seja, a exibição no estádio ou áreas oficiais ou através de imagens de marcas comerciais que não pagaram as exorbitantes taxas de patrocínio à FIFA. Sobre a primazia das motivações comerciais nos megaeventos, ver Mascarenhas (2011).

Horizontes Antropológicos, Porto Alegre, ano 19, n. 40, p. 119-148, jul./dez. 2013 
sobre os estádios de Copa do Mundo e áreas oficiais imediatamente contíguas a eles. Isso era regido pela lei de medidas especiais de 2006. Em particular, o COL foi responsável por toda segurança, controle de acesso e vigilância nos recintos dos estádios e ao redor destes. Para tanto, uma empresa de segurança privada foi indicada pelo comitê, embora [...], a condução da segurança privada tenha enfrentado dificuldades logo no início do torneio. ${ }^{20}$ Através da Lei de Medidas Especiais, os parceiros corporativos e patrocinadores da FIFA gozavam de direitos promocionais exclusivos nos estádios. Esses direitos eram policiados por uma mistura de forças de segurança públicas (principalmente metropolitana) e privadas. Outras áreas oficiais da Copa do Mundo, como os Fan Parks [áreas de aglomeração com eventos gratuitos e venda de produtos oficiais da FIFA] e áreas de exibição pública [de partidas] secundária, eram policiadas pelas forças da ordem locais. (Cornelissen, 2011, p. 3229, tradução minha).

Contudo, é válido ressaltar, no caso das Olimpíadas de Pequim (2008), o governo chinês preservou sua soberania por todo o território, além de controlar unilateralmente todo o aparato de segurança, ao contrário do que aconteceu em 2004, em Atenas, quando esta ficou sob tutela de um consórcio multinacional (Olympic Advisory Security Team) (Samatas, 2011).

Dessa forma, no caso brasileiro, é em relação à criminalidade urbana e à violência cotidiana, assim como à atuação e gerenciamento da segurança pública de modo geral, que o legado de segurança dos megaeventos esportivos deveria ser mais significativo. Vejamos, então, como isso seria obtido.

\section{Integracão institucional: o PESCM14 e o legado de segurança}

A noção de "legado", aquilo que é deixado, que fica, permanece, tem centralidade em praticamente todos os discursos acerca dos megaeventos. Fala-se de legado em urbanismo, em obras de infraestrutura e de transportes, em estádios e instalações esportivas, e também em segurança pública. O termo é usado sem grande debate ou desacordo por praticamente todos os envolvidos com os eventos, desde as entidades privadas promotoras até os manifestantes contrários à sua realização, passando por políticos, moradores

${ }^{20}$ Dentre outras coisas, houve uma greve dos agentes de segurança, reivindicando melhores salários e condições de trabalho, durante a primeira fase da competição. 
das cidades-sedes, representantes de diversas indústrias interessadas, governantes, oposição, empreiteiros, e também acadêmicos. "Legados" são prometidos, esperados, cobrados, lamentados, invejados.

Sem dúvida o legado serve para justificar os gigantescos custos e significativos transtornos trazidos pelos megaeventos, assim como para disfarçar a atenção sobre as muitas suspeitas de corrupção, ilegalidades e superfaturamentos que os prazos e as exigências das entidades promotoras impõem aos organizadores. Não podemos, entretanto, limitar o legado a uma concepção de justificativa, ignorando o quanto há na ideia também de esperança. Não apenas a esperança de que tudo tenha valido a pena, e que algo permaneça para além dos dias de duração dos jogos, mas também de que problemas sociais e urbanos sejam sanados, ou que o país e a cidade se transformem em outra coisa, pretensamente mais moderna, mais desenvolvida. No caso das Olimpíadas no Rio de Janeiro, por exemplo, vem sendo ressaltado por diferentes autores, além de perceptível nos discursos cotidianos, oficiais ou não, a tomada do caso de Barcelona como paradigma a ser seguido (Bienenstein, Mascarenhas; Sánchez, 2011; Gaffney; Oliveira, 2010), como horizonte de transformação desejado.

No que tange à segurança, mais do que um outro lugar, é um outro modelo de atuação que se deseja. Um modelo que se caracterizaria pela atuação coletiva, pela circulação de informações, e pela "modernização tecnológica". Isso é afirmado tanto nos discursos públicos ${ }^{21}$ quanto em textos que orientam a atuação e os preparativos de segurança.

A análise dos documentos oficiais que tratam desse planejamento é uma maneira de ter acesso às promessas de "legado" e aos objetivos da Secretaria Extraordinária de Segurança para Grandes Eventos, do Ministério da Justiça, para a segurança desses eventos. Através do PESCM14 pode-se ter uma ideia inicial a respeito dos gastos previstos com segurança, embora, a julgar pelos últimos megaeventos realizados no mundo, tais valores tendam a ser

${ }^{21}$ Como pode ser visto na fala do ministro da Justiça, José Eduardo Cardozo, na abertura da I Conferência Internacional para a Segurança de Grandes Eventos: "É por meio das relações internacionais que temos condições de construir uma política de segurança pública que nos permita não somente realizar eventos seguros, mas deixar um legado capaz de caracterizar, nos próximos anos, uma mudança de paradigma para a conduta de agentes públicos em todo o território nacional." (Discurso do ministro..., 2012).

Horizontes Antropológicos, Porto Alegre, ano 19, n. 40, p. 119-148, jul./dez. 2013 
constantemente atualizados com a aproximação das competições, com acréscimos substanciais nos gastos inicialmente previstos. ${ }^{22}$

Mesmo uma leitura superficial do PESCM14 deixa patente a importância destacada, quase obsessiva, dada à integração ${ }^{23}$ institucional como horizonte de operacionalidade desejado pelos responsáveis pela segurança dos megaeventos, e como principal legado deixado por estes para a área em questão. O compartilhamento interinstitucional das informações e a coordenação da atuação e integração das diferentes instituições é o novo paradigma almejado. É o que podemos observar nos trechos abaixo:

[...] todos os esforços devem ser direcionados à efetiva integração das instituições brasileiras, e dessas com a Gerência Geral de Segurança do Comitê Organizador da Copa do Mundo FIFA Brasil 2014, pois, como se sabe, a ausência de integração entre os diversos órgãos é um dos grandes fatores que obstaculizam a redução dos índices de criminalidade e desperdiçam recursos públicos. Todo o escopo do planejamento estratégico para a segurança pública durante a Copa do Mundo objetiva à integração das instituições, com consequentes resultados na forma de utilização de recursos humanos, materiais e financeiros. (Brasil, 2012b, p. 13).

O aperfeiçoamento da integração e o desenvolvimento de canais de comunicação e protocolos de relacionamento (a fim de garantir um fluxo de informações que devem ser compartilhadas) têm como meta a concretização da integração entre as instituições de Segurança Pública. Independentemente de quaisquer outras ferramentas administrativas e operacionais colocadas à disposição dos órgãos, a integração definitiva das instituições será o maior de todos os legados e, certamente, justifica a realização da Copa do Mundo de 2014 no Brasil. (Brasil, 2012b, p. 22).

Esse discurso sobre a centralidade da integração institucional a fim de promover um trabalho mais cooperativo e menos fragmentado das diversas instituições em algum grau responsáveis pela segurança dos megaeventos

${ }^{22}$ Londres, no entanto, não se enquadra bem nesse modelo. Os gastos em segurança acabaram sendo inferiores aos que haviam sido previstos (gastou-se menos 39 milhões de libras esterlinas, ou 63 milhões de dólares, do que fora incluído no orçamento). Deve-se ter claro, entretanto, que uma das principais empresas contratadas pelo comitê organizador local, a G4S, informou pouco antes do início do evento que não estaria apta a fornecer os serviços que havia prometido. Para maiores detalhes do orçamento e da crise com a G4S, ver o relatório oficial do governo britânico (United Kingdom, 2012, p. 13).

23 Ao longo das aproximadamente 55 páginas de texto do PECM14, a palavra integração é citada 31 vezes.

Horizontes Antropológicos, Porto Alegre, ano 19, n. 40, p. 119-148, jul./dez. 2013 
coincide com o discurso da cúpula da segurança pública no Rio de Janeiro. No jornal $O$ Globo do dia 8 de dezembro de 2012, por exemplo, em uma reportagem sobre o CICC, é reproduzida uma declaração do secretário de Segurança, José Mariano Beltrame, que reforça a importância de integrar as instituições de segurança, afirmando ser esse também o legado que gostaria de deixar de sua gestão:

Para Beltrame, o prédio representa a concretização da maior meta de sua administração: a sonhada integração das polícias:

- O legado que queremos deixar será a integração de todas as forças de segurança. Isto é um processo tão difícil como ocupar o Alemão. (Bottari, 2012).

Outro indicador é a importância que ganha a Subsecretaria de Planejamento e Integração Operacional da Secretaria de Segurança (Seseg$\mathrm{RJ})$, criada no intuito de comandar a integração das forças policiais do Estado, e que, nas palavras do subsecretário Antônio Roberto de Sá (2012, p. 35):

A Subsecretaria de Planejamento e Integração Operacional, responsável por implantar esse novo modelo de gestão, gradualmente coordenou a integração operacional do policiamento ostensivo com o investigativo. Para isso, foram feitas mudanças estruturais de compatibilização territorial entre Polícia Civil e Militar, visando aumentar a cooperação e integração entre elas.

Tamanha importância e insistência não são injustificadas. Um exemplo paradigmático pode ser retirado do trabalho de campo que realizei em 2008 acompanhando o cotidiano de serviço do sistema de videovigilância do estado do Rio de Janeiro (Cardoso, 2010). Ficaram então evidentes as dificuldades operacionais relacionadas à falta de integração (ou à fragmentação) entre as diferentes instituições e setores institucionais que compunham o sistema, mesmo quando localizados dentro da mesma sala. Um breve exemplo disso pode ser encontrado no seguinte trecho:

$\mathrm{O}$ maior problema de funcionamento daquele $\mathrm{COBAT}^{24}$ dizia respeito à fragmentação descoordenada do trabalho. Na mesa dos operadores ficam alguns telefo-

${ }^{24}$ Centro de Operações do Batalhão. Além do Centro de Comando e Controle, o Cobat do $19^{\circ}$ Batalhão de Polícia Militar do Rio de Janeiro, responsável pelos bairros de Copacabana e Leme, foi o outro ponto da rede de videovigilância onde realizei trabalho de campo, além do CCC. 
nes, para a comunicação com o CCC, a Comtex ${ }^{25}$ e os supervisores da Assegura, ${ }^{26}$ compondo com a câmera que monitora constantemente a sala de operações o sistema de vigilância aos próprios vigilantes. As informações mais importantes para o monitoramento, entretanto, não passam por esses telefones nem pela mesa dos operadores, só chegando a eles através dos policiais despachadores. E como pude perceber diversas vezes, estes nem sempre as repassam para os responsáveis diretos pelo monitoramento. Foi Saulo quem primeiro me alertou para essa questão, com sua insistência em reclamar da fragmentação do seu trabalho. Era ele quem tinha que operar as câmeras e ver as coisas, mas não era ele quem passava, ou recebia, as informações aos agentes nas ruas. Da mesma forma, quando há uma perseguição ou a captura de alguma imagem imediatamente utilizável para policiais que estão nas ruas, são os operadores que comandam as câmeras, mas a comunicação por rádio é feita pelos policiais. A estrutura do trabalho de monitoramento estabelece uma separação definitiva entre olhos de um lado e ouvidos e boca do outro. (Cardoso, 2010, p. 185, grifo do autor).

É também amplamente reconhecida ${ }^{27}$ a histórica rivalidade entre as duas policiais estaduais (civil e militar), que dificulta sobremodo a integração institucional, além da "tradição" de apropriação particular das informações públicas, a fim de utilizá-las como mercadorias políticas (Misse, 2006) na obtenção de vantagens pecuniárias e favores, ou simplesmente como elemento que aumentaria seu poder de negociação e sua liberdade de construção do inquérito. Paes (2008), em seu estudo sobre o Programa Delegacia Legal (também uma forma de promover a integração operacional, no caso em uma mesma instituição, por meio de inovações tecnológicas), relata as dificuldades de operar o sistema devido a estratégias assumidas por policiais insatisfeitos com o "excesso de accountability" da plataforma de informações digital da Polícia Civil. ${ }^{28}$

Compreendem-se, assim, os desafios que deverão ser suplantados para que seja atingida a situação de integração almejada, onde as diferentes instituições possam partilhar informações e trabalhar de forma conjunta e coordenada.

${ }^{25}$ Empresa que fornecia as câmeras responsáveis pelo videomonitoramento.

${ }_{26}$ Fundação assistencial de policiais e bombeiros reformados e aposentados. Era ela quem fornecia a mão de obra para trabalhar como operadores de câmeras de vigilância.

27 Ver, por exemplo, Kant de Lima (1995).

28 "O trabalho investigativo realizado pelo policial é apropriado por ele de forma particular. As estratégias adotadas correspondem a uma forma de os policiais manipularem a justiça, ao mesmo tempo em que fazem com que se mantenha encastelada nas delegacias grande parte de suas atividades e informações." (Paes, 2008, p. 181). 
O reiterado discurso oficial indica que a maneira ideal de atingir esse objetivo é através, principalmente, da combinação entre arquitetura e sistemas tecnológicos/informáticos. Poderíamos então dizer que a aposta da segurança pública brasileira, tendo como incentivo, diretriz e horizonte a realização próxima de megaeventos no país, recai naquilo que Mitchell (1995 apud Duarte; Firmino, 2010, p. 104) chama de arquitetura recombinante, termo usado para "reforçar a ideia de um espaço existente sendo (conceitualmente) diluído por novos paradigmas e recombinado com novos elementos das TICs ${ }^{29}$ ". Isso fica evidenciado se tivermos em conta que o principal pilar desse movimento de integração institucional através da modernização tecnológica é a construção dos Centros de Comando e Controle, como podemos ver no PESCM14:

Os Centros de Comando e Controle não podem ser pensados apenas fisicamente, como instalações tecnológicas de última geração. Eles são, antes de tudo, um arcabouço de procedimentos, protocolos e comunicações previamente estabelecidos, treinados e integrados. (Brasil, 2012b, p. 34-35).

Na estrutura de segurança pública, os Centros de Comando e Controle são de crucial importância. Eles foram pensados de maneira a cobrir toda a necessidade operacional, seja ela internacional, nacional, regional ou local, assim como toda a atividade de Inteligência. Os Centros de Comando e Controle e a capacitação dos recursos humanos dos órgãos envolvidos formam a coluna cervical do sistema de segurança para os Grandes Eventos. (Brasil, 2012b, p. 35).

\section{CICC, ou a integração construída e a doutrina estabilizada: panópticos e zonas tecnológicas}

Mais do que simples prédios, os Centros (Integrados) de Comado e Controle são o elemento basilar da Doutrina militar de comando e controle (Brasil, 2006), adotada oficialmente pelo Ministério da Defesa através da Portaria Normativa $n^{\circ}$ 1888/EMD/MD, de 29 de dezembro de 2006. No documento elaborado pelo ministério, o princípio de comando e controle (ou $\mathrm{C}^{2}$ ) é apresentado como:

29 Tecnologias da informação e comunicação. 
Ciência e arte que trata do funcionamento de uma cadeia de comando e, nessa concepção, envolve, basicamente, três componentes:

a) a autoridade legitimamente investida apoiada por uma organização da qual emanam as decisões que materializam o exercício do comando e para onde fluem as informações necessárias ao exercício do controle;

b) a sistemática de um processo decisório que permite a formulação de ordens, estabelece o fluxo de informações e assegura mecanismos destinados à garantia do cumprimento pleno das ordens; e

c) a estrutura, incluindo pessoal, equipamento, doutrina e tecnologia necessários para a autoridade acompanhar o desenvolvimento das operações. (Brasil, 2006, p. 13).

Além de citada como base de ação no PESCM14 (Brasil, 2012b, p. 34), tais princípios, que em inglês são referidos como C4I (Command, Control, Communication, Computer and Information), nortearam também a política e os investimentos em segurança em megaeventos esportivos anteriores. Samatas (2011) aponta como a adoção do C4I nas Olimpíadas de Atenas, primeira cidade a sediar uma Olimpíada após o 11 de setembro de 2001, representou então uma novidade, tendo posteriormente sido naturalizada como modelo de ação securitária para as cidades que receberiam eventos semelhantes.

No texto da Doutrina militar de comando e controle, o horizonte de atuação num modelo de rede flexivel é afirmado diretamente, em termos bem próximos aos apresentados por Castells (2010), ao se referir à estrutura dominante da nova economia em rede: ${ }^{30}$

A Guerra Centrada em Redes (GCR) é uma forma de atuar na guerra com a visão específica oriunda da era da informação. Caracteriza-se pelo estabelecimento de um ambiente de compartilhamento da consciência situacional, de modo a contribuir para a obtenção da superioridade de informação e da iniciativa, mesmo que os elementos da força estejam dispersos geograficamente. É um conceito novo e que deverá ser acompanhado e aplicado nas oportunidades cabíveis de acordo com as possibilidades das Forças Armadas. (Brasil, 2006, p. 47).

${ }^{30}$ É bastante significativo, nesse sentido, que Castells apareça como referência central para autores que pensam o comando e controle através da ótica da operacionalização da segurança pública, como Coli (2011, p. 14). 
O sistema deverá ter capacidade para ser reconfigurado rapidamente e para responder a uma iminente mudança de ambiente. A Flexibilidade poderá ser obtida por projetos de sistemas inteligentes e pela possibilidade de utilização de instalações fixas, móveis e transportáveis.Para atender a esse princípio, a estrutura [...] deverá ser capaz de agregar ou incorporar produtos e conceitos derivados de inovações tecnológicas, além de adequar-se às condições impostas por reestruturações administrativas ou às alterações nos quadros político e estratégico (Brasil, 2006, p. 19).

Ou, como afirmam Mendes Afonso e Santos da Silva (2013, p. 11),

ações comandadas e controladas de forma integrada, apoiando-se nas técnicas de $\mathrm{C} 2$, proporcionam uma rápida e precisa formação de consciência situacional, permitindo aos responsáveis um uso mais racional e objetivo dos meios disponíveis e, sem dúvida, uma resposta mais rápida e precisa às demandas que se apresentam.

No caso específico do Rio de Janeiro, a construção do Centro Integrado de Comando e Controle (CICC) ${ }^{31}$ estava inicialmente prevista para ser concluída no final de 2010, ${ }^{32}$ porém foi com dois anos de atraso, e considerável acréscimo dos gastos, que apenas a primeira fase da construção - ou seja, o prédio, sem a infraestrutura tecnológica - foi acabada. A inauguração oficial foi realizada em 31 de maio de 2013, ainda sem que o prédio estivesse operando de forma completa. Em publicação de janeiro de 2012, o governador do estado apresenta a obra como "um projeto essencial para a segurança pública", afirmando que sua inauguração ocorreria em breve e que o CICC "abrigará um dos mais modernos sistemas de atendimento e monitoramento do mundo"; o investimento no projeto seria, segundo suas palavras, de 36 milhões de reais (Entrevista..., 2012, p. 9). Vale ressaltar que, em 2009, o Tribunal de Justiça do Rio de Janeiro assinou um convênio com o governo do estado, através do qual liberava 60 milhões de reais para a implementação do CICC (Bargains, 2009); em dezembro de 2011 o Ministério da Justiça também liberou R\$ 18.432.588,94 com o mesmo objetivo (Brasil, 2011); e que,

31 Ver o material de divulgação da SESEG (Rio de Janeiro, 2009).

${ }^{32}$ Ver declaração do governador Sérgio Cabral publicada no Diário Oficial (Dargains, 2009).

Horizontes Antropológicos, Porto Alegre, ano 19, n. 40, p. 119-148, jul./dez. 2013 
apenas no dia 31 do mesmo mês em que essa entrevista é publicada (janeiro de 2012), são assinados pelo secretário de Segurança e o diretor-presidente da Empresa de Obras Públicas do estado três termos aditivos ao contrato de construção no valor de R $\$ 32.843 .538,40$ (Diário Oficial do Estado do Rio de Janeiro, 2012a, 2012b). Em reportagem do jornal $O$ Globo, de 8 de dezembro de 2012, é anunciado que o valor final da obra tinha ficado em 102,8 milhões de reais (Bottari, 2012), aumentado ainda até a data da inauguração para 104,5 milhões (Machado, 2013), ou seja, custou 290,28\% do valor que inicialmente havia sido anunciado.

Como principal novidade do CICC, em seu espaço físico estarão representadas as diversas instituições oficiais responsáveis pela segurança pública e "defesa social": SAMU, Corpo de Bombeiros, CET-Rio, Polícia Rodoviária Federal, Guarda Municipal, Defesa Civil e as polícias civil e militar (ver Figura 1 para a distribuição espacial). Na ocorrência de crises a serem gerenciadas ou durante a realização dos grandes eventos, na sala preparada para esse intuito também estariam presentes representantes da Polícia Federal, da Abin e das Forças Armadas.

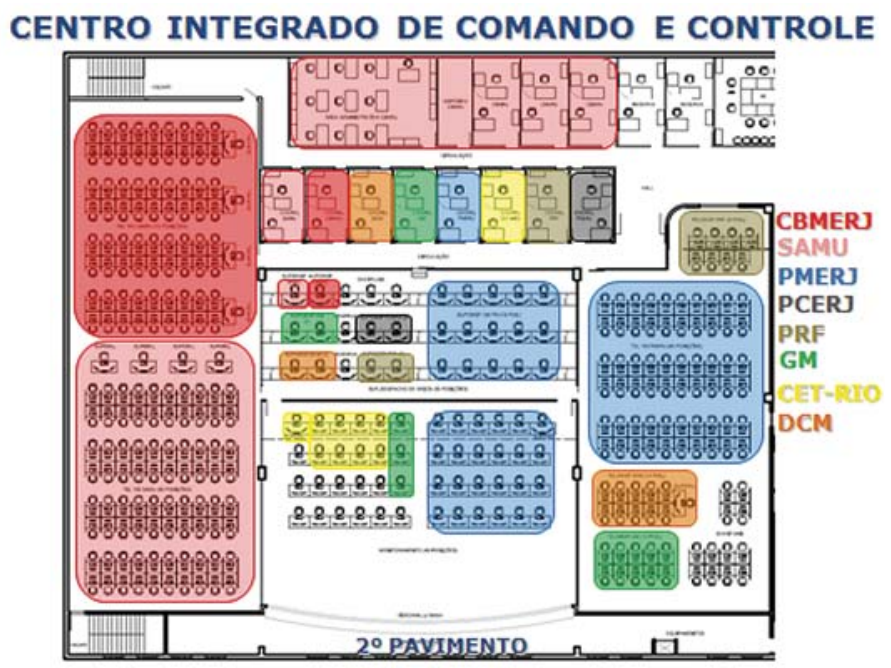

Figura 1. Planta baixa do segundo pavimento do CICC do Rio de Janeiro (Coli, 2001, p. 71). 
O Centro Integrado de Comando e Controle foi concebido como um aperfeiçoamento estrategicamente planejado do Centro de Comando e Controle, ${ }^{33}$ ponto nevrálgico do sistema de videomonitoramento da Secretaria de Segurança, que, desde 2005, a Polícia Militar opera na região metropolitana da capital (Rio de Janeiro, Niterói e Baixada Fluminense). ${ }^{34} \mathrm{O}_{\mathrm{CCC}}{ }^{35}$ era localizado na torre da Central do Brasil, espaço que, embora tivesse sido adaptado ao seu funcionamento, contava com limitações estruturais de difícil transposição para a inevitável expansão do sistema de câmeras, e para a realização de um trabalho mais integrado e coordenado com outras instituições públicas implicadas na segurança. Um exemplo paradigmático é que um centro de gerenciamento de crises, presente no projeto original do $\mathrm{CCC}$, mas não concretizado, é parte importante do projeto do CICC, sendo ressaltado o papel central que desempenhará durante a realização de grandes eventos. A transposição para um novo prédio, construído especificamente para tal função, pretende proporcionar uma oportunidade ímpar para a elaboração, e posterior execução, de uma planificação definida e de longa duração para esse modelo de atuação em segurança pública (ao menos é o que afirmam os discursos oficiais).

A transformação trazida pelo conceito de integração, que constitui a principal diferença entre os dois centros, fica evidenciada na comparação das diretrizes ligadas ao espaço físico destinados ao seu funcionamento. No CCC, o sistema de videovigilância era operado basicamente pela PM, com maior conexão com o Corpo de Bombeiros, instituição com a qual havia, ao menos, um canal de comunicação direto. E, pelas dimensões do espaço disponível, a incorporação de outras instituições mostrava-se inviável. Além disso, por se tratar de um prédio bastante antigo, nem sempre era possível a instalação da infraestrutura tecnológica necessária para os planos de modernização. É o que Horan (2000 apud Duarte; Firmino, 2010, p. 109) chama de adaptative design,

${ }^{33}$ A ênfase na integração esperada fica evidenciada na diferença entre o nome dos dois centros de comando e controle, CCC e CICC.

${ }^{34}$ A Subsecretaria de Modernização Tecnológica (SsMT), criada pela Seseg há pouco mais de três anos, é a principal responsável pelo CICC e também pela adequação tecnológica da segurança pública do Rio de Janeiro, necessária à realização dos megaeventos esportivos. O Centro de Comando e Controle, quando de sua criação, era de responsabilidade da Subsecretaria de Planejamento e Integração Operacional. O atual subsecretário, Edval Moreira de Novaes Junior, está na Seseg desde janeiro de 2007, inicialmente como subsecretário de Inteligência, e no ano seguinte mudando para a recém-inaugurada SsMT.

${ }^{35}$ Para informações mais detalhadas do CCC e de seu funcionamento, ver Cardoso (2010). 
"onde o espaço é adaptado para inclusão de infraestrutura, equipamentos e novas práticas devido às TICs" - sendo a construção de um novo prédio, que já levaria em conta tanto os sistemas informáticos e de comunicação previstos quanto a presença de todas as instituições que se deseja integrar, um caso de transformative design, onde especificações técnicas e novas práticas de uso das TICs são "incorporadas, infiltradas e recombinadas com os elementos tradicionais da arquitetura". Como apontam Duarte e Firmino (2010, p. 109):

Essa classificação de design ou espaços recombinantes proposta por Horan direciona as discussões para uma diferenciação entre espaços tradicionais adaptados e espaços conceitualmente novos onde a cibernética já estaria afetando os processos de concepção, construção e uso dos lugares. Em outras palavras, a classificação de Horan serve para verificar o nível de simbiose entre elementos tradicionais do espaço (tijolos e argamassa) e os elementos telemáticos (redes, bits e bytes).

O CICC contém, em uma construção, o modelo do que deve ser a atuação das forças de segurança. A planta baixa do segundo pavimento do CICC do Rio de Janeiro, apresentada na Figura 1, indica o papel da arquitetura na integração das diferentes instituições, todas localizadas em uma mesma ala do prédio, lado a lado. Transformações arquitetônicas semelhantes não são novidade, tendo seguido diferentes preceitos em diferentes épocas. Exemplos significativos são a criação da figura do corredor, concomitante ao fortalecimento dos conceitos de esfera pública, vida privada e individualismo (Habermas, 1984), ${ }^{36}$ e, sem dúvidas, o panóptico, projeto de Jeremy Bentham (2000), cuja análise posteriormente foi retomada por Foucault (2003) como exemplo paradigmático do planejamento disciplinar. ${ }^{37} \mathrm{~A}$ similaridade com o princípio panóptico advém menos do trabalho de vigilância e observação, e mais da tentativa de conformação das atividades humana e institucional através do planejamento arquitetural (a arquitetura é pensada como artifício para reformar o compor-

${ }^{36}$ O corredor permitia a circulação pelo imóvel sem que isso implicasse a passagem pelos quartos, que foram cada vez mais ganhando contornos de espaço privado por excelência, evidenciada pelo uso corrente da expressão "entre quatro paredes" para indicar o máximo possível de intimidade e privacidade.

37 Ao longo das obras de Foucault, em diversos momentos é ressaltada a importância da arquitetura na criação de espaços governados que garantissem e reproduzissem modelos de poder (por exemplo, Foucault, 2009, 2011). São também variados os trabalhos contemporâneos sobre o assunto megaeventos que foram influenciados por essa concepção - ver, por exemplo, Gaffney (2010), Klauser (2011) e Giulianotti (2011).

Horizontes Antropológicos, Porto Alegre, ano 19, n. 40, p. 119-148, jul./dez. 2013 
tamento e assujeitar os indivíduos). Nesse sentido, esses centros, ao reunirem todos os elementos constitutivos do comando e controle, são construídos para estabilizar materialmente, tornar durável (Latour, 1998) uma determinada rede sociotécnica, preconizada pelos princípios de uma doutrina de atuação militar (Walker et al., 2009). Os documentos através dos quais essa doutrina é especificada, também fazem, obviamente, parte da rede sociotécnica construída e estabilizada com a construção do prédio e sua distribuição espacial interna.

Entretanto, embora a influência do espaço físico seja amplamente ressaltada, em iniciativas contemporâneas baseadas na modernização tecnológica, a integração e coordenação devem passar principalmente pelas tecnologias de comunicação e pela circulação de informações, além da mera concentração de pessoas. Assim, o estabelecimento de uma zona tecnológica (Barry, 2001) (38 $^{38}$ é fundamental para que o projeto do $\mathrm{CICC}$, e a política de ação integrada/ coordenada em segurança, possam fazer uso dos meios técnicos que lhes são oferecidos.

Uma zona tecnológica não é um espaço físico ou um território, sendo formada por conexões estabelecidas entre pontos que devem ser relativamente similares tecnologicamente: mesmo com diferentes graus de conhecimento, interesse e atuação, todas as partes devem ser capazes de se comunicar sem grandes distorções através de uma mesma linguagem tecnológica. Entretanto, a escolha e o estabelecimento dessa linguagem comum, ou dos padrões de conduta, dos softwares utilizados, das estratégias de atuação, de monitoramento, mostram-se sempre como um dos principais desafios no estabelecimento de zonas tecnológicas de ação coordenada. É o que indica, por exemplo, a fala do subsecretário de Modernização Tecnológica, Edval Novaes (2012, p. 28, grifo meu):

Como no Centro Integrado funcionarão oito forças diferentes, quatro estaduais, uma federal e três municipais, nós desenvolvemos também um software de atendimento e despacho, chamado de Teleatendimento Integrado de Demandas Emergenciais (TIDE). O TIDE funcionará dentro do próprio CICC, porque nós vamos levar para o Centro Integrado os teleatendimentos de emergência, como o 190, que é o atendimento da polícia; o 193, do Corpo de Bombeiros; e o 192, do Serviço de Atendimento Móvel de Urgência (SAMU). Este é, com certeza,

38 Andrew Barry (2001, p. 2, tradução minha) fala de uma sociedade tecnológica na qual viveríamos, "na medida em que tecnologias específicas dominam nosso senso dos tipos de problemas que o governo e a política devem abordar e as soluções que devem ser adotadas”. 
um trabalho de integração e inovação. [...] Com a integração de todos esses órgãos e, mais do que isso, com a integração através do software de TIDE, passaremos a ter um banco de dados único. [...] todas as demandas emergenciais vão convergir para um local comum. A partir daí, esperamos tirar muitos dados estratégicos para, de alguma maneira, retroalimentar a inteligência para análise e estudos futuros.

Da mesma forma, no PESCM14, fica patente que a integração esperada se dará também através da criação de uma zona tecnológica específica, formada pelo "Sistema Nacional de Informações", sendo a participação nesse sistema usada como condição necessária para o repasse de recursos federais aos estados:

O recebimento de recursos da União estará condicionado à participação de cada ente federativo envolvido no "Sistema Nacional de Informações". Como suporte, a União lhes oferecerá treinamento e capacitação de seus recursos humanos. O objetivo dessa vinculação é a viabilização de um plano nacional de combate à violência, a partir dos registros realizados no Sistema Nacional de Informação. (Brasil, 2012b, p. 33).

Uma zona tecnológica também não é ou tem uma estrutura fixa, dentro da qual a ação ocorre. É um processo que demanda constante regeneração, ajuste e reconfiguração. $\mathrm{O}$ trabalho de manutenção precisa ser incorporado, não apenas como uma forma de resolver problemas e imprevistos, mas como parte fundamental do sistema tecnológico. O investimento inicial em aquisição e instalação de aparelhos, câmeras, computadores e redes, acaba representando, em pouco tempo, apenas uma parcela reduzida dos gastos em modernização, devido aos elevados custos do aperfeiçoamento pessoal, manutenção e da quase sempre inevitável expansão dos sistemas. Nesse sentido, afirma Novaes (2012, p. 28):

Um dos nossos maiores desafios é o processo de aquisição, por exemplo, de um software, que é difícil visualizar ou mensurar. Para nós, essa questão é bastante complicada. Afinal, precisamos manter a tecnologia atualizada e equilibrar o orçamento e a velocidade nos processos licitatórios.

Para além da dificuldade de criar uma zona tecnológica, outra questão prática surge quando se trata de sistemas públicos ou de segurança: 
a imprescindibilidade de delimitação e controle de suas fronteiras. As mesmas tecnologias de comunicação que possibilitam a integração e a coordenação do trabalho e das diferentes instituições trazem a ameaça de invasão ou boicote do sistema, situação recorrente e conhecida como hackerismo, ou ciberataques. ${ }^{39} \mathrm{O}$ funcionamento dos sistemas informáticos precisa, então, ser aberto o suficiente para que a comunicação interinstitucional integre os diferentes atores responsáveis pela segurança pública no Rio de Janeiro, mas ao mesmo tempo deve ter um grau considerável de fechamento para que seja protegida a confidencialidade daquelas informações e minimizada a vulnerabilidade do sistema diante de suas principais ameaças externas, assim como para manter uma mínima autonomia das instituições. ${ }^{40}$

A integração dos sistemas de informações não significará a abertura completa dos bancos dados de cada uma das instituições e não colocará em risco a preservação de informações sigilosas. Caso uma consulta realizada por uma força policial apresente resultado positivo para a existência de um registro criminal em outra unidade da federação, a Instituição interessada deverá checar o conteúdo da informação junto àquela que inseriu os dados no sistema, a fim de obter os dados intercambiáveis. (Brasil, 2012b, p. 33).

Tendo em vista essa necessidade de estabelecimento de barreiras no interior de zonas tecnológicas, deve-se salientar que continua havendo uma dependência/centralidade do trabalho realizado por humanos, e não automaticamente por sistemas tecnológicos, na integração institucional. Como observara ao pesquisar o funcionamento do $\mathrm{CCC}$, ocorre uma operação discursiva que minimiza o caráter sociotécnico ${ }^{41}$ desses sistemas tecnológicos, aquilo que

39 Prova do reconhecido aumento da importância conferida a essas ameaças é que no PESCM14 são identificados quatro tipos de espaço que devem ser protegidos pelas forças de segurança: para além dos tradicionais espaços terrestre, aéreo e marítimo, aparece também o espaço cibernético (Brasil, 2012b, p. 26).

40 Essa preocupação e as dificuldades práticas que trazem, aparecem também no texto de Mendes Afonso e Santos da Silva (2013, p. 11): "Neste ponto, esbarra-se na questão cultural, porque, não raro, alguns dirigentes entendem que estarão, por conta dessa integração, abrindo mão de seu poder decisório e permitindo uma ingerência externa, alterando a estrutura e a autonomia de sua agência."

41 Dimensão coletiva e híbrida dos sistemas tecnológicos em funcionamento (ver Law, 2003; Callon, 2003; Latour, 2000; Akrich, 1993). Além de serem formadas pela atuação conjunta de humanos e não humanos organizados em rede, se caracterizam pela ausência de fixidez e por só existirem efetivamente quando atualizados pela realização prática.

Horizontes Antropológicos, Porto Alegre, ano 19, n. 40, p. 119-148, jul./dez. 2013 
chamei de sobredeterminação técnica ${ }^{42}$ ou a ideia de que a aquisição de avançados meios técnicos permitiria que os resultados prometidos fossem alcançados de forma quase automática. É colocada demasiada ênfase na tecnologia em si, enquanto os homens que interagem de modo direto com o sistema tecnológico são tratados como intermediários, ou seja, como elementos neutros, necessários apenas para fazer funcionar o sistema, quando na prática agem como mediadores, que "transformam, traduzem, distorcem e modificam o sentido ou elementos que devem transportar" (Latour, 2007, p. 58). As pessoas são não apenas imprescindíveis para o funcionamento do sistema, mas são, de forma imbricada com elementos técnicos, o próprio sistema. Retomo aqui, a título de ilustração desse fator, algumas das conclusões que cheguei ao final do trabalho etnográfico realizado no sistema de videomonitoramento policial do Rio de Janeiro (Cardoso, 2010, p. 231-232, grifo do autor):

A experiência e o olhar maldoso dos operadores são lembrados pelos "voluntários" do $19^{\circ} \mathrm{BPM}$, policiais do CCC e pelo supervisor (representando os "discursos oficiais" da Polícia Militar e da Secretaria de Segurança Pública), como valorosas armas no desempenho do monitoramento. No entanto, sem os objetos técnicos, esse olhar maldoso nada veria além das paredes da sala e da movimentação dos colegas, e teriam que guardar as imagens apenas na memória (humana). Já as câmeras e o aparato tecnológico que as sustentam, são louvadas pelas amplas possibilidades de deslocamento espacial e de eternização do visualizado, fatores responsáveis pela especificidade da vigilância eletrônica. Contudo, estes apenas captam informações, que codificam e transmitem em linguagem numérica, cuja recomposição em imagens e em cenas depende dos mediadores humanos, seu olhar e sua capacidade interpretativa. A relação (negligenciada) entre os dois tipos de elementos - pessoas e tecnologia - é o âmago da videovigilância, mas também sua parte mais problemática, e menos levada em conta. Ao manterem na penumbra a relação entre os elementos humanos e maquínicos é possível, estratégica e discursivamente, que as vantagens do sistema sejam enaltecidas e ressaltadas, enquanto suas fraquezas são mascaradas.

${ }^{42}$ No caso que estudei, chamava de sobredeterminação técnica "a premissa de que um sistema de videovigilância seria constituído principalmente por câmeras, computadores e a estrutura material que estes precisam para operar, enquanto o olhar, a percepção e a comunicação humanas ocupariam um papel secundário, pouco importante. Desse modo, o investimento em mão de obra é posto sempre em segundo plano." (Cardoso, 2011).

Horizontes Antropológicos, Porto Alegre, ano 19, n. 40, p. 119-148, jul./dez. 2013 
E essas pessoas, acrescento, não são apenas constituintes de um único sistema, ou agenciamento sociotécnico (Callon, 2003), mas de uma série deles nas diversas atividades que realizam. No caso da integração institucional, haverá um pertencimento simultâneo a uma instituição de segurança específica, de estrutura burocrática, hierárquica e vertical, e a um sistema integrado de segurança, com características estruturais mais próximas de uma rede horizontal e flexível (Castells, 2010). Ou - aquilo que temos até agora -, um projeto de criação e estabilização de redes através da adoção simultânea de princípios organizacionais e tecnologias de informação (tentando tornar materialmente durável a doutrina conhecida como comando e controle). Diante desse panorama, são consideráveis as possibilidades de surgimento de interesses, procedimentos ou interpretações conflitantes, dificultando o processo de integração institucional desejado. É um tanto mais difícil - e real - a lida com mediadores, ao invés de intermediários, fato que fica evidente no funcionamento prático de inúmeras inovações tecnológicas.

\section{Considerações iniciais (parte final)}

Ao tratar de eventos que ainda estão por acontecer - embora o fato de serem "mega" faz com que comecem a ocorrer muito antes, desde a escolha da sede, incluindo os longos, complexos e custosos preparativos - não se pode almejar encerrar o texto com conclusões, ou considerações finais. Pode-se, no máximo, avançar um pouco nas considerações iniciais, aquelas que embora precedam o acontecimento, podem fornecer uma base mais sólida para compreendê-lo e analisá-lo. E foi isso que busquei ao longo deste artigo, com o auxílio da bibliografia relativa à segurança nos megaeventos esportivos, principalmente, na última década, e da análise do planejamento estratégico de segurança para a Copa de 2014. Com base nessas informações e fontes, me interesso por um aspecto que vem sendo apontado como central no "legado" a ser deixado por esses megaeventos, e que justificaria, ao menos parcialmente, os grandes investimentos realizados no campo da segurança: a integração institucional, a ser realizada por meio de um processo de modernização tecnológica e de transformação/criação arquitetural. Daí a importância do Centro Integrado de Comando e Controle, obra de custo mais elevado na área de segurança, e apontado como principal pilar para o modelo desejado pelos planejadores da segurança pública local. 
Contudo, para que o trabalho de pesquisa possa avançar, será preciso que o funcionamento prático do CICC, e o acontecimento dos megaeventos, tornem-se realidade. Após isso, poderemos averiguar se a criação de redes e de zonas tecnológicas foram bem feitas e suficientes para alterar algumas características isolacionistas das instituições de segurança pública; se os dois anos de atraso e os investimentos de mais de 100 milhões de reais num prédio justificam o legado a ser deixado pelos megaeventos; e, finalmente, se o caminho da modernização tecnológica pode, de forma duradoura, representar uma verdadeira transformação nos paradigmas da segurança pública no Rio de Janeiro.

Até lá, só podemos esperar, e continuar construindo e desconstruindo bases, por isso mesmo cada vez mais sólidas, para que, chegado o momento, possamos aproveitá-lo, analisá-lo e compreendê-lo de modo mais substancial.

\section{Referências}

AGOSTINO, G. Vencer ou morrer: futebol, geopolítica e identidade nacional. Rio de Janeiro: Mauad; Faperj. 2002.

AKRICH, M. Les objets techniques et leurs utilisateurs, de la conception à l'action. Raisons pratiques, n. 4, p. 35-57, 1993.

ARMSTRONG, G.; GIULIANOTTI, R. From another angle. Police surveillance and football supporters. In: NORRIS, C.; MORAN, J.; ARMSTRONG, G. (Ed.). Surveillance: closed circuit television and social control. Aldershot: Ashgate, 1998. p. 113-138.

BARRY, A. Political machines: governing a technological society. London: Athlone Press, 2001.

BENTHAM, J. O Panóptico. In: SILVA, T. T. (Org.). O Panóptico/Jeremy Bentham. Belo Horizonte: Autêntica, 2000. p. 11-74.

BENNET, C.; HAGGERTY, K. (Org.). Security games: surveillance and control at mega-events. London: Routledge, 2011.

BIENENSTEIN, G.; MASCARENHAS, G.; SÁNCHEZ, F. O jogo continua: megaeventos esportivos e cidades. Rio de Janeiro: EdUerj; Faperj, 2011. 
BOTTARI, E. Centro de Comando e Controle vai monitorar o Rio com 950 câmeras. $O$ Globo, 8 dez. 2012. Disponível em: <http://oglobo.globo. com/rio/centro-de-comando-controle-vai-monitorar-rio-com-950-cameras6986434\#ixzz2FGaICNhU>. Acesso em: 16 dez. 2012.

BRASIL. Ministério da Defesa. Doutrina militar de comando e controle. Brasília, 2006. Disponível em: <http://www.defesa.mil.br/arquivos/File/ legislacao/emcfa/publicacoes/md31_d_03_doutrina_milc2_1a_ed2006.pdf $>$. Acesso em: 30 dez. 2012.

BRASIL. Subsecretaria de Planejamento, Orçamento e Administração. Coordenação-Geral de Logística. Extratos de convênios. Diário Oficial da União, seção 3, p. 123, 29 dez. 2011. Disponível em: <http://www.jusbrasil. com.br/diarios/33390640/dou-secao-3-29-12-2011-pg-123>. Acesso em: 30 dez. 2012.

BRASIL. Ministério da Justiça. Secretaria Extraordinária de Segurança para Grandes Eventos. I Conferência Internacional de Segurança para Grandes Eventos: programação da conferência. Brasília, 2012a. Disponível em: $<$ http:// blog.justica.gov.br/inicio/wp-content/uploads/2012/11/PROGRAMAÇÃOOFICIAL-DA-CONFERÊNCIA-SISGE.pdf $>$. Acesso em: 30 dez. 2012.

BRASIL. Ministério da Justiça. Secretaria Extraordinária de Segurança para Grandes Eventos. Planejamento estratégico de segurança para a Copa do Mundo FIFA Brasil 2014. Brasília, 2012b. Disponível em: <http://blog.justica. gov.br/inicio/wp-content/uploads/2012/11/PROGRAMAÇÃO-OFICIALDA-CONFERÊNCIA-SISGE.pdf>. Acesso em: 30 dez. 2012.

CALLON, M. Quel espace publique pour la démocratie technique? In: CEFAÏ, D.; PASQUIER, D. (Org.). Les sens du public: publics politiques, publics médiatiques. Paris: CURAPP; PUF, 2003. p. 197-221.

CARDOSO, B. V. Todos os olhos: videovigilâncias, videovoyeurismos e (re) produção imagética na tecnologia digital. Tese (Doutorado em Antropologia Cultural)-Instituto de Filosofia e Ciências Sociais, Universidade Federal do Rio de Janeiro, Rio de Janeiro, 2010. 
CARDOSO, B. V. Vigilantes eletrônicos no Rio de Janeiro: agenciamentos sociotécnicos e pesquisa em tecnologia. Configurações, Porto, v. 8, p. 97-108, 2011

CASTELLS, M. A sociedade em rede: volume I. São Paulo: Paz e Terra, 2010.

COAFFEE, J.; FUSSEY, P.; MOORE, C. Laminated security for London 2012: Enhancing security infrastructures to defend mega sporting events. Urban Studies, v. 48, n. 15, p. 3311-3327, 2011.

COLI, A. Centro Integrado de Comando e Controle (CICC): ferramenta de integração para o Estado Rede. Monografia (Especialização em Segurança Pública)-Academia de Polícia Militar de Minas Gerais e Escola de Governo Professor Paulo Neves de Carvalho da Fundação João Pinheiro, Belo Horizonte, 2011.

CORNELISSEN, S. Mega event securitisation in a Third World setting: Glocal processes and ramifications during the 2010 FIFA Wold Cup. Urban Studies, v. 48, n. 15 , p. $3221-3240,2011$.

CURI, M. Espaços da emoção: arquitetura futebolística, torcida e segurança pública. Tese (Doutorado em Antropologia)-Instituto de Ciências Humanas e Filosofia, Universidade Federal Fluminense, Niterói, 2012.

DARGAINS, J. Estado e TJ firmam convênio para construção de Centro Integrado de Comando e Controle. Diário Oficial do Estado do Rio de Janeiro, Rio de Janeiro, 17 dez. 2009. Notícias, p. 1. Disponível em: $<$ http://www. jusbrasil.com.br/diarios/4965418/pg-1-do-noticias-diario-oficial-do-estadodo-rio-de-janeiro-doerj-de-17-12-2009>. Acesso em: 30 dez. 2012.

DIÁRIO OFICIAL DO ESTADO DO RIO DE JANEIRO. Rio de Janeiro, 2 fev. 2012a. Poder Executivo, p. 7. Disponível em: <http://www.jusbrasil.com. br/diarios/34098688/doerj-poder-executivo-02-02-2012-pg-7>. Acesso em: 30 dez. 2012.

DIÁRIO OFICIAL DO ESTADO DO RIO DE JANEIRO. Rio de Janeiro, 2 fev. 2012b. Poder Executivo, p. 8. Disponível em: <http://www.jusbrasil.com. br/diarios/34098689/doerj-poder-executivo-02-02-2012-pg-8>. Acesso em: 30 dez. 2012. 
DISCURSO DO MINISTRO da Justiça na I Conferência Internacional de Segurança para Grandes Eventos. 8 nov. 2012. Disponível em: $<$ https:// soundcloud.com/blogdajustica3/discurso-do-ministro-da-justi $>$. Acesso em: 30 dez. 2012.

DUARTE, F.; FIRMINO, R. Espaço, visibilidade e tecnologias: (re) caracterizando a experiência urbana. In: BRUNO, F.; KANASHIRO, M.; FIRMINO, R. Vigilância e visibilidade: espaço, tecnologia e identificação. Porto Alegre: Sulina, 2010. p. 94-112.

ENTREVISTA COM GOVERNADOR SÉRGIO CABRAL. Cadernos FGV Projetos: Segurança Pública em Foco, ano 6, n. 18, p. 6-13, jan. 2012.

FIFA. Safety regulations. Zurich, 2008. Disponível em: $<$ http://www.fifa.com/ $\mathrm{mm} /$ document/tournament/competition/51/53/98/safetyregulationse.pdf $>$. Acesso em: 2 dez. 2012.

FORÇAS ARMADAS fazem exercício de segurança para a Copa das Confederações. Portal da Copa, 25 maio 2013. Disponível em: <http:// www.copa2014.gov.br/pt-br/noticia/forcas-armadas-fazem-exercicio-deseguranca-para-a-copa-das-confederacoes $>$. Acesso em: 4 jun. 2013.

FOUCAULT, M. Vigiar e punir: nascimento da prisão. Petrópolis: Vozes, 2003.

FOUCAULT, M. Segurança, território, população. São Paulo: Martins Fontes, 2009.

FOUCAULT, M. Microfisica do poder. São Paulo: Graal, 2011.

GAFFNEY, C. Mega-events and socio-spatial dynamic in Rio de Janeiro, 1919-2016. Journal of Latin American Geography, v. 9, p. 7-29, 2010.

GAFFNEY, C.; OLIVEIRA, N. G. Rio de Janeiro e Barcelona: os limites do paradigma olímpico. Cuadernos Críticos de Geografia Humana, Barcelona, v. 15, n. 895 (17), 2010. Disponível em: <http://www.ub.edu/geocrit/b3w895/b3w-895-17.htm>. Acesso em: 2 dez. 2012. 
GIULIANOTTI, R. Sport mega events, urban football carnivals and securitised commodification: The case of the English Premier League. Urban Studies, v. 48, n. 15, p. 3293-3310, 2011.

GIULIANOTTI, R.; KLAUSER, F. Security governance and sport megaevents: Toward an interdisciplinary research agenda. Journal of Sport and Social Issues, v. 34, p. 49-61, 2009.

GIULIANOTTI, R.; KLAUSER, F. Security and surveillance at sport mega events. Urban Studies, v. 48, n. 15, p. 3157-3168, 2011.

HABERMAS, J. Mudança estrutural na esfera pública. Rio de Janeiro: Tempo Brasileiro, 1984.

KANT DE LIMA, R. A polícia da cidade do Rio de Janeiro: seus dilemas e paradoxos. Rio de Janeiro: Forense, 1995.

KLAUSER, F. The exemplification of 'Fan Zones': Mediating mechanisms in the reproduction of best practices for security and branding at Euro 2008. Urban Studies, v. 48, n. 15, p. 3203-3219, 2011.

LATOUR, B. La tecnología es la sociedad hecha para que dure. In: DOMENÈCH, M.; TIRADO, F. (Org.). Sociología simétrica: ensayos sobre ciencia, tecnología y sociedad. Barcelona: Gedisa, 1998. p. 109-142.

LATOUR, B. La fin des moyens. Réseaux, v. 18, n. 100, p. 39-58, 2000.

LATOUR, B. Changer de société, refaire de la sociologie. Paris: La Découverte, 2007.

LAW, J. Notes on the Theory of Actor Network: Ordering, strategy and heterogeneity. Lancaster: Centre for Science Studies, Lancaster University, 2003. Disponível em: < http://www.lancs.ac.uk/fass/sociology/research/ publications/papers/law-notes-on-ant.pdf $>$. Acesso em: 2 dez. 2012.

MACHADO, M. RJ inaugura centro operacional para monitorar grandes eventos. G1, 31 maio 2013. Disponível em: <http://m.g1.globo.com/riode-janeiro/noticia/2013/05/rj-inaugura-centro-operacional-para-monitorargrandes-eventos.html>. Acesso em: 31 maio 2013. 
MASCARENHAS, G. Desenvolvimento urbano e grandes eventos esportivos: o legado olímpico nas cidades. In: BIENENSTEIN, G.; MASCARENHAS, G.; SÁNCHEZ, F. O jogo continua: megaeventos esportivos e cidades. Rio de Janeiro: EdUerj; Faperj, 2011. p. 27-39.

MEMBROS do comitê da Rio-2016 são acusados de roubar documentos de Londres-2012. Esportes Brasil, 21 set. 2012. Disponível em: $<\mathrm{http}: / /$ www.espbr.com/noticias/membros-comite-rio-2016-sao-acusados-roubardocumentos-londres-2012>. Acesso em: 2 dez. 2012.

MENDES AFONSO, S.; SANTOS DA SILVA, A. Comando e controle: a ótica da defesa social. Tecnologia \& Defesa - Segurança, São Paulo, v. 8, p. 10-12, 2013.

MISSE, M. Crime e violência no Brasil contemporâneo: estudos de sociologia do crime e da violência urbana. Rio de Janeiro: Lúmen Júris, 2006.

NOVAES, E. Tecnologia a serviço da segurança (depoimento). Cadernos FGV Projetos: Segurança pública em foco, ano 6, n. 18, p. 26-31, 2012.

PAES, V. Quem domina a regra do jogo: sobre a reforma da polícia e os registros policiais. In: MISSE, M. (Org.). Acusados \& acusadores: estudos sobre ofensas, acusações e incriminações. Rio de Janeiro: Revan, 2008. p. 165-185.

RIO DE JANEIRO. Secretaria de Estado de Segurança. Novo Centro Integrado de Comando e Controle. 2009. Disponível em: <http://www.4shared.com/ file/175182890/159728f3/Video_CICC_RJ.html>. Acesso em: 2 dez. 2012. Vídeo.

SÁ, A. R. C. de. Integração e gestão por resultados em segurança pública (depoimento). Cadernos FGV Projetos: Segurança pública em foco, ano 6, n. 18 , p. 32-37, 2012.

SAMATAS, M. Surveillance in Athens 2004 and Beijing 2008: A comparison of the olympic surveillance modalities and legacies in two different olympic host regimes. Urban Studies, v. 48, n. 15, p. 3347-3366, 2011. 
UNITED KINGDOM. London 2012 Olympic and Paralympic Games Quarterly Report. Oct. 2012. Disponível em: <http://www.culture.gov.uk/ images/publications/DCMS_GOE_Quarterly_Report_Q3.pdf>. Acesso em: 16 dez. 2012.

WALKER, G. et al. Command and control: the sociotechnical perspective. Surrey: Ashgate, 2009.

Recebido em: $31 / 12 / 2012$

Aprovado em: 04/06/2013 